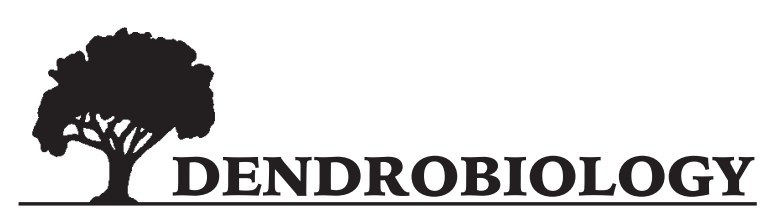

2016, vol. 76, 3-11

http://dx.doi.org/10.12657/denbio.076.001

\author{
Vicente Rozas, Carlos Le Quesne, Ariel Muñoz, Paulina Puchi
}

\title{
Climate and growth of Podocarpus salignus in Valdivia, Chile
}

Received: 25 September 2015; Accepted: 4 May 2016

\begin{abstract}
Little dendroclimatic research has been conducted on species of Podocarpus, in response to inherent difficulties associated with tree-ring differentiation and cross-dating. We sampled complete stem cross sections from a plantation of Podocarpus salignus trees in Valdivia, Chile, near the southern edge of the species' range. We measured earlywood, latewood, and total ring widths avoiding ring wedging, and we calculated the corresponding chronologies. The relationship of these chronologies with maximum temperature, precipitation, and sea level pressure was addressed using correlation and redundancy analyses. All chronologies showed a similar response to climate that was consistent with the cloudy, rainy, and temperate conditions of the study area. That is, warm and dry conditions during previous late springs were beneficial, while warm and rainy winters under low atmospheric pressures were detrimental for growth. The observed climatic responses are in contrast to those of conifers from mountainous areas of southern South America. Limitation of carbohydrates available for growth in the following active season was a possible cause for the observed responses to climate. That is, high winter temperatures may deplete stored carbohydrates by increasing respiration, and a high degree of cloud cover reduces the radiation received by the trees in the active season, which may hamper photosynthesis. Our work highlights the dendroclimatological value of Podocarpus salignus to investigate the influence of climatic variation on tree growth and forest productivity.
\end{abstract}

Keywords: dendrochronology, precipitation, sea level pressure, southern South America, temperature

Addresses: V. Rozas, C. Le Quesne, Laboratorio de Dendrocronología y Cambio Global, Facultad de Ciencias Forestales y Recursos Naturales, Universidad Austral de Chile, Casilla 567, Valdivia, Chile, e-mail: vicenterozas@gmail.com

A. Muñoz, P. Puchi, Instituto de Geografía, Facultad de Ciencias del Mar y Geografía, Pontificia

Universidad Católica de Valparaíso, Avenida Brasil 2241, Valparaíso, Chile

\section{Introduction}

The genus Podocarpus includes 105 species distributed throughout tropical, subtropical, and warm temperate areas mainly in the Southern Hemisphere (Farjon, 2001). This genus occurs in Australia, New Zealand, New Caledonia, Southeast Asia, Japan, Africa, and South and Central America (Kelch, 1997).
Dendrochronological research on Podocarpus species is scarce as a consequence of inherent difficulties associated with poorly-defined tree-ring boundaries, lobate growth, ring wedging, and multiple or missing rings (Norton \& Ogden, 1990; Bauch et al., 2006; Krepkowski et al., 2011; McDougall et al., 2012). These traits hamper effective cross-dating among tree-ring series from coexisting trees, and even from 
the same tree. For instance, February \& Stock (1998) stated that the South African species P. latifolius (Thunb.) R.Br. ex Mirb. and P. falcatus (Thunb.) Endl. are not useful for dendrochronological analysis as a consequence of its lobate growth and the formation of multiple rings per year. In contrast, tree-ring series from P. totara G. Benn. ex D. Don and P. hallii Kirk were successfully cross-dated in New Zealand (Dunwiddie, 1979; Norton et al., 1987). However, even when tree-ring series were successfully cross-dated, Wells (1972) found that chronologies of $P$. hallii in New Zealand were insensitive to climate. In southern Chile, tree-ring chronologies were developed from cross-dated ring width series measured on increment cores of P. nubigenus Lindl. (Lamprecht, 1984; Sweda \& Inoue, 1987), but no clear statistical links with climate were found. However, recent studies have shown that tree-ring series measured on stem cross sections of Podocarpus can be successfully cross-dated and significant correlations of the resulting chronologies with climate can be calculated (Krepkowski et al., 2012; McDougall et al., 2012). The use of cross sections has been recommended to overcome the difficulties for tree-ring cross-dating typical of Podocarpus sp. (Norton et al., 1987; Norton \& Ogden, 1990).

Two species of Podocarpus are endemic to southern South America. The most austral species is $P$. nubigenus. This species occurs in the temperate forests of southern Chile and south-western Argentina between $38-53^{\circ} \mathrm{S}$. The more northerly species, $P$. salignus D. Don., occurs in south-central Chile be- tween 35-41ºS (Rodríguez et al., 1983). P. salignus is threatened by habitat loss (Farjon \& Page, 1999; Hechenleitner et al., 2005). In general, this species is associated with water-courses in the northern part of its range, and occurs in the understory of rainy temperate forests mainly dominated by Nothofagus obliqua (Mirb.) Oerst. in the southern part of its range (Rodríguez et al., 1983). Phylogenetically, P. salignus is more strongly associated with the P. smithii de Laub., an endemic species to Queensland, Australia, than with other Podocarpus species from South America (Biffin et al., 2011).

Little is known about the climatic factors that control tree growth in the temperate rainy forests of the Valdivian region in southern Chile, particularly of $P$. salignus. To date, no examination of the potential for dendrochronology, or attempt to produce a chronology of this species, has been reported. The objective of this research was to evaluate the influence of Valdivian climate on $P$. salignus radial growth, considering its earlywood, latewood, and complete tree rings.

\section{Materials and methods}

\section{Site description}

The study site is located in the Arboretum of Universidad Austral de Chile in Isla Teja, Valdivia, Chile $\left(39^{\circ} 48^{\prime} 51^{\prime \prime}\right.$ S, $\left.73^{\circ} 14^{\prime} 45^{\prime \prime} \mathrm{W}\right)$, which contains a plantation of $P$. salignus within the species' natural
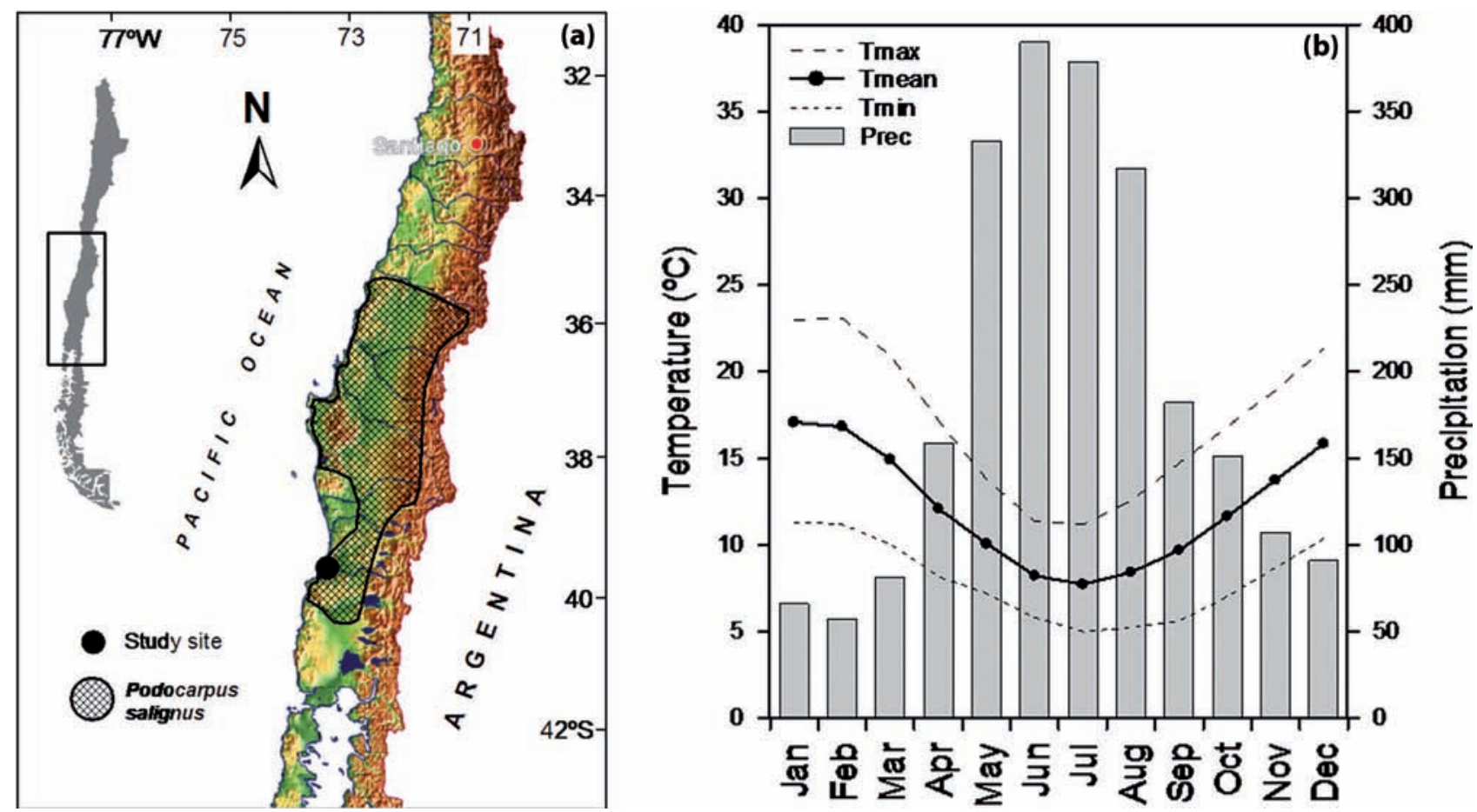

Fig. 1. Study site location within the natural distribution range of Podocarpus salignus in Chile (a), based on Hechenleitner et al. (2005). Climatic diagram of Isla Teja, Valdivia, period 1960-2010 (b). Tmax: maximum temperature; Tmean: mean temperature; Tmin: minimum temperature; Prec: precipitation 
range (Fig. 1a). The Arboretum covers 54 ha and is one of the most important botanical collections of Chile. Soils are deep, clayish, and with high organic matter content, formed on old volcanic ash deposed on metamorphic schist. Soil is acidic, with a value of $\mathrm{pH}$ around 5, and shows high total nitrogen and interchangeable aluminum content, but low levels of extractable bases, especially phosphorous (Gerding et al., 2006).

\section{Sampling, sample processing, and dendrochronological analyses}

In May 2009, 14 trees were logged for thinning purposes (i.e. to reduce the density of trees) in a $P$. salignus plantation. The trees were grown from saplings of locally-source seed and were planted during 1975-9 within a regular $2 \times 2 \mathrm{~m}$ scheme (Fig. $2 \mathrm{a}$ ). We took complete basal stem cross sections from the logged trees to analyze tree-ring series. There is a greatest advantage of plantation-grown material for dendrochronological work with Podocarpus species where trees can be cut down and a full stem disc can be used.
The cross sections were processed according to conventional dendrochronological procedures (Speer, 2010), including wood drying and sanding with progressively finer sandpaper from 100 to 800 grains $\mathrm{cm}^{-2}$. When wood cellular elements were clearly visible under magnification, the complete cross sections were scanned at high resolution and saved into a TIFF file. Two tree-ring series per section were selected for measuring, avoiding ring wedging found in the sections (Fig. 2b). Boundaries between consecutive tree rings, and between earlywood (EW) and latewood (LW) within every ring, were detected and the corresponding widths of EW, LW, and total rings (TR) were measured to the nearest $0.001 \mathrm{~mm}$ using WinDENDRO ${ }^{\circledR}$ software (Regent Instruments Inc.) in the Instituto de Geografía, Pontificia Universidad Católica de Valparaíso. This software facilitates automatic and interactive recognition and measurement of tree-ring widths on digital images of wood cores or sections (Guay et al., 1992). Tree-ring series were cross-dated following the criteria for the southern hemisphere, assigning to every ring the year in which growth started. This dating was verified with the program COFECHA (Grissino-Mayer, 2001).
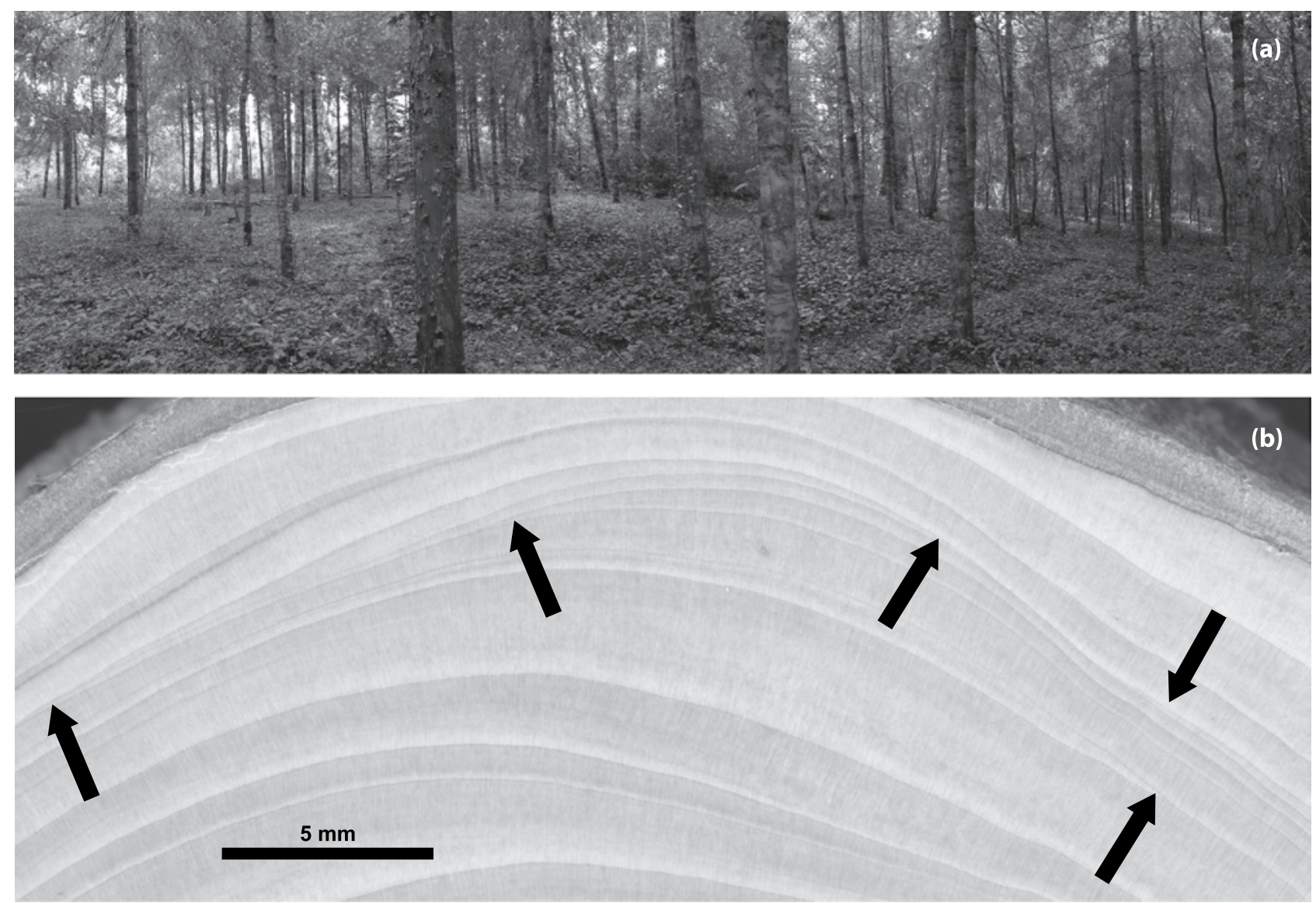

Fig. 2. Plantation of $P$. salignus in the Arboretum of Universidad Austral de Chile, Isla Teja, Valdivia, Chile, in which stem cross sections were sampled (a). Sector of a stem cross section showing local ring wedging (black arrows) with the complete rings locally absent (b) 
Raw series of EW, LW, and TR were standardized and then averaged on a year-to-year basis to obtain mean chronologies of radial growth. The software ARSTAN (Cook \& Holmes, 1996) was used to calculate the standardized chronologies of EW, LW, and TR after a double procedure of trend removal. A linear or negative exponential model was fitted to every raw series, and a cubic spline function with a $50 \%$ frequency response of $32 \mathrm{yr}$ was fitted to the obtained residuals. Autoregressive modelling was also applied, which produced growth indices with minimized autocorrelation of the growth series. Individual series of indices for EW, LW, or TR were averaged into a site chronology by biweight robust mean (Cook \& Holmes, 1996). The statistical quality of EW, LW, and TR chronologies was assessed using the standard statistics mean sensitivity, signal-to-noise ratio, mean between-tree correlation, and expressed population signal (Speer, 2010).

\section{Climate data}

We used monthly time series of precipitation and temperature for the 1960-2010 period recorded in the meteorological station of Isla Teja, Valdivia, located at an elevation of $9 \mathrm{~m}$ a.s.l. and $1.4 \mathrm{~km}$ from the study site. Mean annual precipitation is $2310 \mathrm{~mm}$ and mean annual temperature is $12.17^{\circ} \mathrm{C}$, with mean of minimum temperatures of $7.95{ }^{\circ} \mathrm{C}$, and mean of maximum temperatures of $17.04^{\circ} \mathrm{C}$. May, June, July, and August are the rainiest months, with more than $300 \mathrm{~mm}$ per month, while December, January, February, and March are the driest, with monthly precipitation lower than $100 \mathrm{~mm}$ (Fig. 1b). December, January, and February are the warmest months, with mean temperatures ranging between 13 and $19^{\circ} \mathrm{C}$, and maximum temperatures ranging between 18 and $27^{\circ} \mathrm{C}$. The coldest months are June, July, and August, with mean temperatures ranging between 5 and 11 ${ }^{\circ} \mathrm{C}$ (Fig. 1b). In addition, since atmospheric pressure variability causes the weather experienced locally, monthly gridded time series of mean sea-level pressure (SLP) for the study area were obtained from the datasets of the Climate Research Unit (CRU), University of East Anglia, UK, accessible from the web site of the Royal Netherlands Meteorological Institute (http://climexp.knmi.nl/).

\section{Calculation of growth-to-climate relationships}

Statistical relations between tree-ring chronologies and climatic time series were studied in 1978-2009, the period with at least 10 trees and 20 tree-ring series in the chronologies (Fig. 3a). Pearson's correlation was used to calculate the relations between EW, LW, and TR chronologies, and monthly mean maximum temperature (Tmax), total precipitation (Prec), and mean SLP. The growth variance explained by climate on tree-ring chronologies was determined by means of redundancy analysis (RDA), a canonical multivariate method that seeks linear combinations of environmental predictors correlated to linear combinations of response variables (Legendre \& Legendre, 1998). Index chronologies for EW, LW, and TR were used as response variables in RDA and climatic variables revealed as significant by correlation analyses were used as environmental predictors. Stepwise RDAs were calculated to determine the amount of growth variance explained by each predictor, which was given by the canonical eigenvalue $\lambda$. Monte Carlo tests with 999 random iterations were used to evaluate the significance of canonical eigenvalues. Partial RDA analyses (pRDA) were also preformed to estimate the shared effect of the climatic variables (Tmax, Prec, and SLP) on the tree-ring chronologies. Total variance in tree-ring chronologies explained by climate was obtained under a reduced RDA model, including the combined effects of all significant climatic predictors. A bi-variate scatterplot of the weighting coefficients for the first two RDA axes displayed the relationships between the climatic predictors and tree-ring chronologies. RDA analyses were performed with the software CANOCO v4.0 for Windows (Braak \& Šmilauer, 1998).
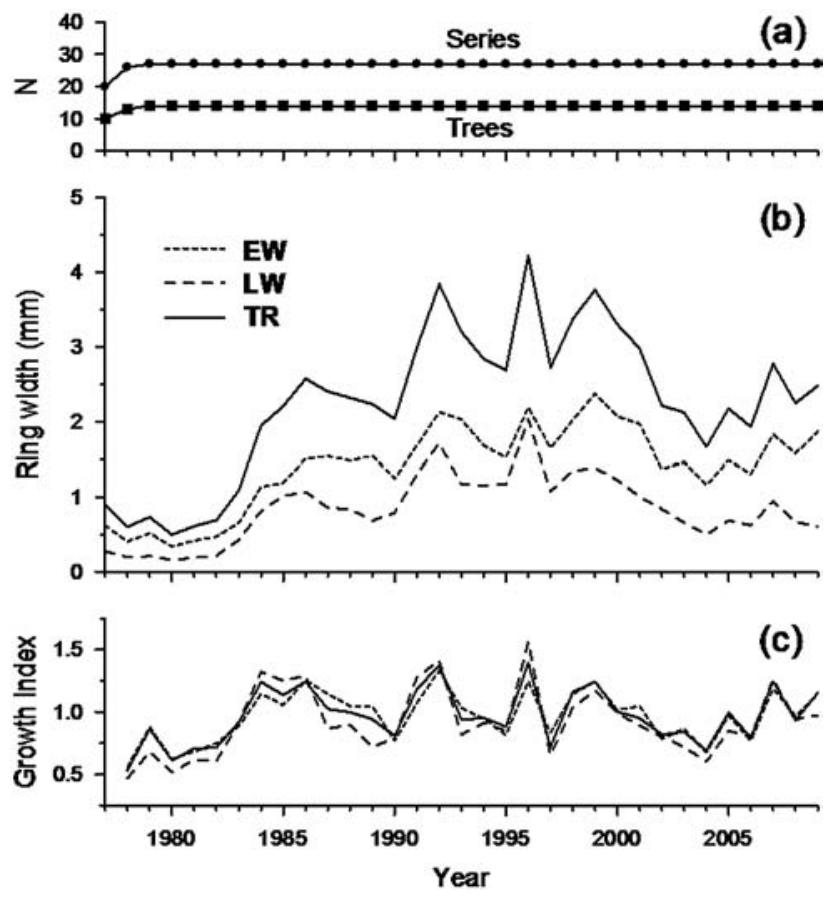

Fig. 3. Annual variation of sample sizes $(\mathrm{N})$ of tree-ring series and trees (a), mean EW, LW, and TR widths (b), and standardized tree-ring growth indices of EW, LW, and TR for P. salignus (c) 


\section{Results}

Mean diameter of cross sections used for this study was $14.05 \mathrm{~cm}$, with a standard deviation of $4.12 \mathrm{~cm}$. The chronologies were calculated based on 27 series from 14 trees. Mean growth chronologies for EW, LW, and TR showed quite similar patterns, with an initial period of reduced growth from 1978 to 1983 , a period of released growth between 1984 and 2001, and a growth reduction in 2004 (Fig. 3b). Mean widths were larger for EW than for LW (Table 1), with a mean percentage of latewood within a ring of $35.94 \%$. The chronologies of growth indices also showed a similar interannual variation pattern for EW, LW, and TR (Fig. 3c). Correlations among chronologies were highly significant in all cases (Table 1). Mean sensitivity was higher for the LW chronology than for the EW and TR chronologies, indicating a larger relative change between consecutive rings for latewood than for earlywood and total tree-ring width. However, the signal-to-noise ratio, the mean between-trees correlation, and the expressed population signal were higher for TR chronology than for EW and LW chronologies, suggesting a larger strength of the common signal for total tree-ring widths than for earlywood and latewood widths (Table 1).

Correlations with maximum temperature were positive in previous November for EW, LW, and TR chronologies, but negative in June for LW and TR chronologies (Fig. 4a). The patterns of significant correlations with precipitation and SLP were opposite, showing negative correlations with precipitation in previous November and July for EW, LW, and TR chronologies (Fig. 4b), but positive correlations with SLP in previous November for EW and TR, and in July for EW, LW, and TR (Fig. 4c).

Considered individually, the EW, LW, and TR chronologies were more strongly related to particular climatic predictors. A strong relation was found for the EW chronology with maximum temperature in previous November (Fig. 5a). By contrast, the climatic driver most strongly related to the LW chronology was July SLP (Fig. 5b). In the case of TR chronology, the most influential climatic factor was July precipitation (Fig. 5c). The chronologies were also negative- ly related to total annual precipitation, mainly EW and TR chronologies $(\mathrm{r}=-0.48, \mathrm{p}=0.003$ for EW; $\mathrm{r}=-0.42, \mathrm{p}=0.013$ for $\mathrm{LW} ; \mathrm{r}=-0.49, \mathrm{p}=0.003$ for TR).

RDA analyses showed that maximum temperature was the most important climatic predictor

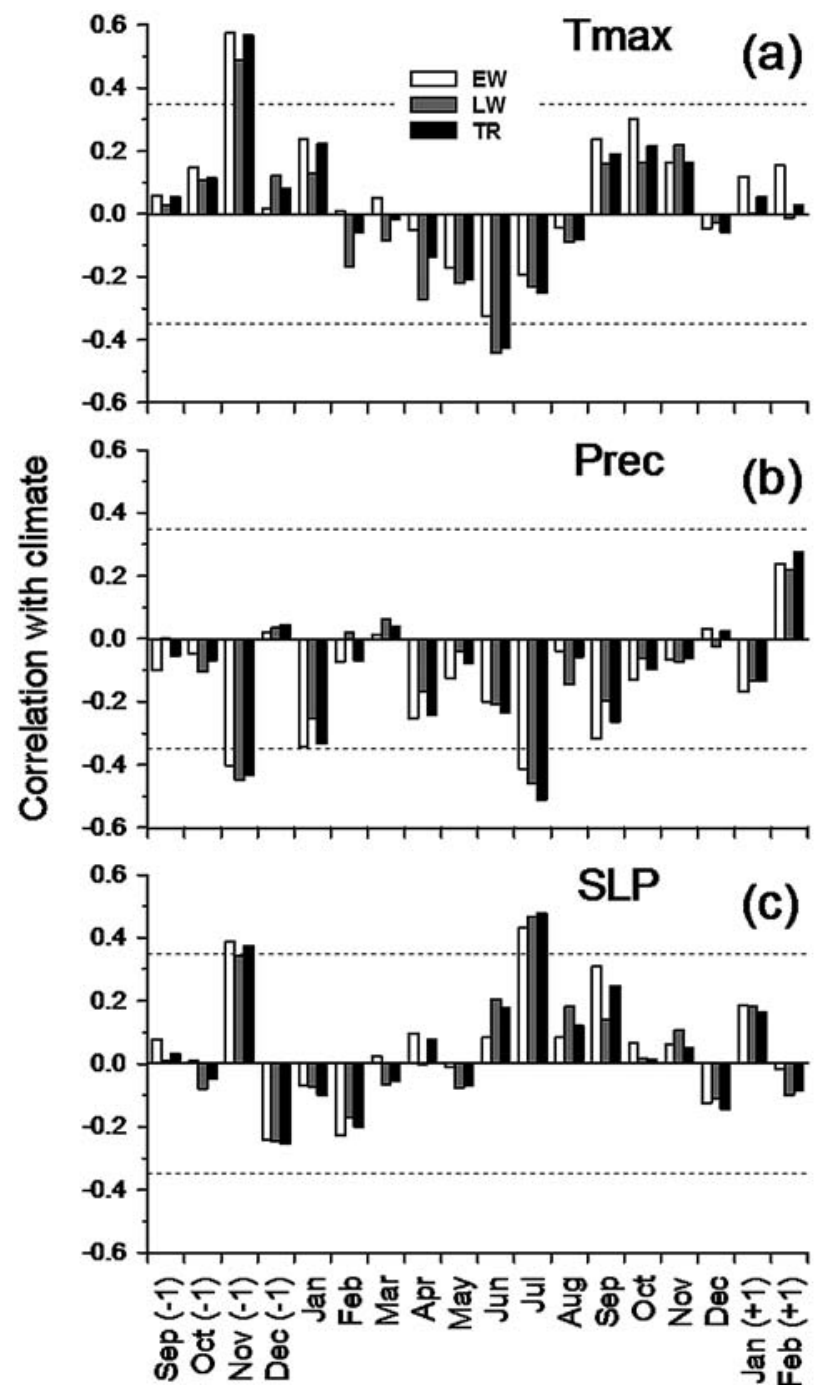

Fig. 4. Correlation functions for P. salignus radial growth in Isla Teja, Valdivia, for the period 1978-2009. Horizontal dashed lines indicate the significance intervals $(\mathrm{p}<0.05)$ for correlation coefficients. $(-1)$ and $(+1)$ indicate the years previous and following those year in which growth started, respectively

Table 1. Standard statistics for EW, LW, and TR chronologies of Podocarpus salignus, and correlations between chronologies calculated in 1978-2009, the period with at least 10 trees and 20 tree-ring series in the chronologies. MW: mean width of raw data $(\mathrm{mm})$, SD: standard deviation $(\mathrm{mm})$, MS: mean sensitivity, SNR: signal-to-noise ratio, RBT: mean between-trees correlation, EPS: expressed population signal. Lower-left half of the matrix includes the correlations between chronologies, upper-right half includes their statistical significances

\begin{tabular}{cccccccc}
\hline \multirow{2}{*}{ Chronology } & \multirow{2}{*}{ MW \pm SD } & \multicolumn{3}{c}{ Statistics } & \multicolumn{2}{c}{ Matrix of correlations } \\
\cline { 3 - 7 } & & MS & SNR & RBT & EPS & EW & LW \\
\hline EW & $1.42 \pm 0.39$ & 0.244 & 4.66 & 0.264 & 0.823 & $<0.001$ & $<0.001$ \\
LW & $0.84 \pm 0.23$ & 0.258 & 4.60 & 0.261 & 0.822 & 0.859 & $<0.001$ \\
TR & $2.26 \pm 0.57$ & 0.223 & 8.47 & 0.377 & 0.894 & 0.957 & 0.954 \\
\hline
\end{tabular}



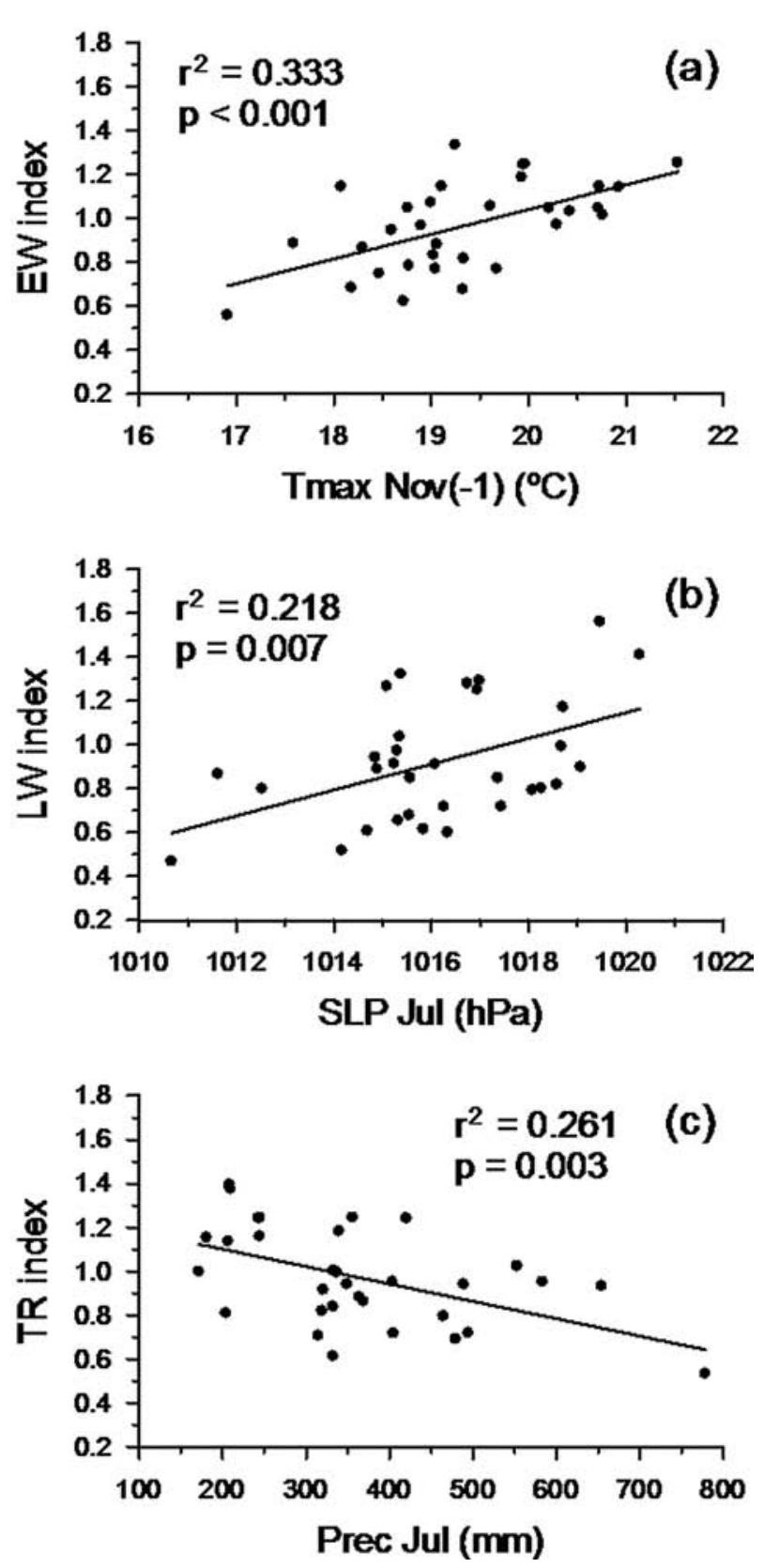

Fig. 5. Relationships between the climatic factors most relevant for $P$. salignus growth and the indices of EW (a), LW (b), and TR (c) chronologies. The coefficients of determination $\left(\mathrm{r}^{2}\right)$ and their statistical significances $(\mathrm{p})$ are shown

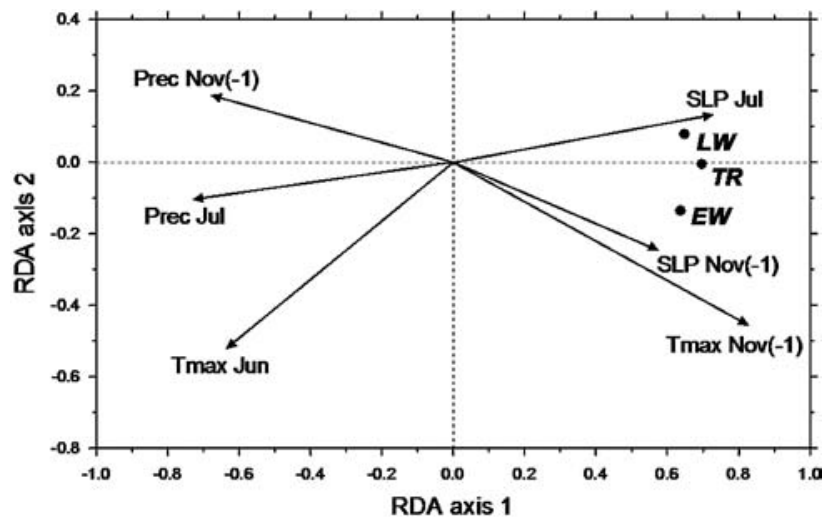

Fig. 6. RDA bi-variate scatterplot showing the relationships between $P$. salignus EW, LW, and TR chronologies and the significant $(\mathrm{p}<0.05)$ climatic variables, according to a whole reduced RDA model. In a RDA bi-variate scatterplot, the correlation between environmental predictors and response variables is given by the angle between two vectors or arrows. Climatic predictors with long vectors are the most significant in RDA analysis. Vectors pointing in a similar direction indicate a positive correlation, vectors almost perpendicular indicate a null correlation, and vectors in opposite directions indicate a negative correlation

controlling radial growth of $P$. salignus, with $38.0 \%$ of growth variance explained by maximum temperature variation (Table 2 ). The other climatic predictors with a significant effect on growth, precipitation and SLP, explained 29.6 and $23.3 \%$ of growth variance, respectively. A significant shared effect of maximum temperature and SLP was revealed by pRDA analyses, with $19.4 \%$ of growth variance explained by this interaction, while the combinations maximum temperature-precipitation and precipitation-SLP did not show significant shared effects on growth variation (Table 2). The reduced RDA model, accounting for the overall effect of all the significant climatic predictors together, showed that climate explained $44.5 \%$ of $P$. salignus growth variation.

The two groups of significant climatic predictors on tree growth revealed by correlations were confirmed by the RDA bi-variate scatterplot (Fig. 6). Climatic drivers that improved $P$. salignus growth were

Table 2. Summary statistics of redundancy analysis (RDA) and partial redundancy analysis (pRDA) models for the relationships between the variation of EW, LW, and TR growth indices and the climate predictors for maximum temperature (Tmax), precipitation (Prec), and seal level pressure (SLP). (-1) indicates the year previous to growth. The proportion of tree-ring growth variation accounted for by each model was quantified by the eigenvalue $\lambda$

\begin{tabular}{|c|c|c|c|c|c|}
\hline Model & Predictors & Covariables & $\lambda$ & F-value & P-value \\
\hline $\mathrm{RDA}$ & Tmax Nov(-1), Tmax Jun & & 0.380 & 8.89 & 0.001 \\
\hline $\mathrm{RDA}$ & Prec Nov(-1), Prec Jul & & 0.296 & 6.08 & 0.008 \\
\hline $\mathrm{RDA}$ & SLP Nov(-1), SLP Jul & & 0.233 & 4.39 & 0.025 \\
\hline pRDA & Tmax Nov(-1), Tmax Jun & Prec Nov(-1), Prec Jul & 0.130 & 3.04 & 0.051 \\
\hline pRDA & Tmax Nov(-1), Tmax Jun & SLP Nov(-1), SLP Jul & 0.194 & 4.57 & 0.012 \\
\hline pRDA & Prec Nov(-1), Prec Jul & SLP Nov(-1), SLP Jul & 0.091 & 1.81 & 0.184 \\
\hline Reduced RDA & Tmax, Prec, SLP & & 0.445 & 3.34 & 0.013 \\
\hline
\end{tabular}


SLP in July and previous November, and maximum temperature in previous November. Climatic drivers detrimental for growth were precipitation in July and previous November, and maximum temperature in June. Some of these climatic factors showed to be inter-related, as were the cases of maximum temperature in previous November, negatively related to both precipitation in previous November $(\mathrm{r}=-0.47$, $\mathrm{p}=0.005)$ and July $(\mathrm{r}=-0.51, \mathrm{p}=0.003)$, and positively to previous November SLP $(r=0.54, \mathrm{p}=$ $0.001)$. Other significant negative correlations were between precipitation and SLP in previous November $(\mathrm{r}=-0.50, \mathrm{p}=0.003)$ and July $(\mathrm{r}=-0.68, \mathrm{p}$ $<0.001)$.

\section{Discussion}

Growth patterns observed in the cross sections probably revealed the history of the plantation. Slow growth in the period 1978-1983 may correspond to an initial phase of sapling establishment and competition with underlying vegetation. The released growth in 1984-2001 may correspond to the phase of canopy formation, when crowns of trees were big enough to outcompete the surrounding vegetation. Finally, the growth reduction in 2004 may correspond to the phase of canopy closure, with convergence of individual crowns and initiation of inter-tree competition.

The mean percentage of latewood within a ring of $35.94 \%$ was considerably larger than those normally observed in natural populations of $P$. salignus (C. Le Quesne and A. Muñoz, personal observations). This may be related to the dominance and reduced competition of young trees in a plantation, showing a longer period of growth than the suppressed trees in the understory of deciduous forests, where this species normally occurs in the study area (Rodríguez et al., 1983). In a 40-year-old plantation of Abies alba Mill., for instance, cambial activity started earlier, stopped later, and lasted longer in dominant trees than in intermediate and suppressed ones (Rathgeber et al., 2011), which implied the formation of a wider latewood within wider tree rings. $P$. salignus may show a broad growth period in Valdivia, particularly those trees growing in a plantation under low competition levels, which may cause the formation of a wider latewood in comparison to trees growing under natural conditions.

The percentage of latewood within a ring in the case of $P$. salignus in Valdivia was similar to those reported in other dendrochronological studies. As an example, a dendroclimatological study in ten stands of Pinus pinaster Ait. showed that the percentage of latewood within a ring ranged between 30.0 and $45.6 \%$ (Rozas et al., 2011). Chronology statistics were generally higher for $\mathrm{TR}$, a result that may be related to a higher year-to-year variability and a larger amount of growth variation related to climate in total tree-ring widths than for EW and LW. Statistics of $P$. salignus chronologies were lower than statistics from the alpine species P. lawrencei Hook.f. in Australia (McDougall et al., 2012), suggesting a lower climatic sensitivity of growth in Valdivia than in mountain regions.

All chronologies responded similarly to climate. This response is indicated by the highly significant correlations between chronologies. The main climatic signal was related to previous November conditions, indicating that a warm and dry late spring is beneficial for growth of $P$. salignus in Valdivia. This response is consistent with those of $P$. lawrencei in Australian alpine areas, which showed a positive response to maximum temperature and negative to precipitation in previous October and November (McDougall et al., 2012). A similar response has been described for Pinus canariensis C. Sm. ex DC. growing under cloudy conditions in the Canary Islands, with a negative response to precipitation in previous spring (Rozas et al., 2013). Low atmospheric pressure increases cloudiness and rainfall, but reduces temperature in the study area (Aravena \& Luckman, 2009; González-Reyes \& Muñoz, 2013). Limitation of the synthesis of carbohydrates due to cloudiness and low temperatures was the most probable cause for the observed responses to climate. Low maximum temperatures and a reduced radiation received by the trees due to high cloud cover commonly reduce the photosynthetic rates and the amount of carbohydrates available for growth in the following active season, as has been previously established (Graham et al., 2003; Min \& Wang, 2008).

The second climatic signal observed in the chronologies was related to winter conditions, particularly the negative effects of June maximum temperature and July precipitation. Warm and rainy winters are associated with low atmospheric pressures, which showed to be detrimental for $P$. salignus growth in Valdivia, and more particularly for latewood growth. High winter temperatures may deplete carbohydrates by increasing respiration when photosynthetic activity in evergreen conifers is reduced and their loss cannot be reloaded (Ögren, 1997). In addition, the negative response of conifer growth to winter precipitation showed to be widespread under wet climates in the Northern Hemisphere (Peterson \& Peterson, 2001; Thomsen, 2001; Mäkinen et al., 2002; Rozas et al., 2011), and related to conditions of soil water surplus and cloudiness in the rainy season. The declining trend of winter precipitation recorded in Valdivia during the last decades (Gonzalez-Reyes \& Muñoz, 2013) suggests that the detrimental impact of rainfall on $P$. salignus growth would decrease in 
the future. The negative responses to precipitation observed for P. salignus in Valdivia were opposite to those found in other conifers growing in mountain areas of southern South America under water-limited conditions, such as Araucaria araucana (Molina) K. Koch, Austrocedrus chilensis (D.Don) Pic. Serm. \& Bizzarri, and Pilgerodendron uviferum (D.Don) Florin whose radial growth was improved by rainfall occurrence (Le Quesne et al., 2006; Aravena, 2007; Muñoz et al., 2014).

This work highlights the value of Podocarpus salignus to investigate the influence of climatic variation on tree growth and forest productivity, in spite of the particular difficulties typical of this genus for treering differentiation and cross-dating. Complete stem cross sections were sampled from a plantation of young trees growing under uniform conditions and without external disturbances. We showed that $P$. salignus growth was sensitive to climatic factors consistent with the cloudy, rainy, and temperate conditions in Valdivia, Chile, near the southern range edge of the species. Results from this research show the potential for dendroclimatic investigation at low elevations in Chile. We are planning further research in both artificial plantations and natural populations of $P$. salignus in order to obtain a deeper understanding of the modulation of growth by climate in the Valdivian region.

\section{Acknowledgement}

We gratefully acknowledge the valuable collaboration of Robert Brümmer for providing the climatic data from the meteorological station of Isla Teja, Valdivia, and of Paul Sheppard for English language assistance and useful suggestions on an earlier draft of this paper. This research was founded by the projects FONDECYT 1121106 and FONDECYT 1151427. The stay of V. Rozas in Universidad Austral de Chile, Valdivia, was founded by CONICYT through the Concurso Nacional "Atracción de Capital Humano Avanzado del Extranjero, Modalidad Estadías Cortas (MEC)" (code 80130061).

\section{References}

Aravena JC (2007) Reconstruction of climate variability from tree-ring records and glacier fluctuations in the southern Chilean Andes. Ph.D. Geography (Environmental Sciences) University of Western Ontario, London-Ontario, Canada.

Aravena JC \& Luckman BH (2009) Spatio-temporal rainfall patterns in Southern South America. International Journal of Climatology 29: 2106-2120.

Bauch J, Quiros L, Noldt G \& Schmidt P (2006) Study on the wood anatomy, annual wood incre- ment and intra-annual growth dynamics of Podocarpus oleifolius var. macrostachyus from Costa Rica. Journal of Applied Botany and Food Quality 80: $19-24$.

Biffin E, Conran JG \& Lowe AJ (2011) Podocarp evolution, a molecular phylogenetic perspective: Ecology of the Podocarpaceae in tropical forests (ed. by BL Turner \& LA Cernusak) Smithsonian Contributions to Botany, number 95, Smithsonian Institution Scholarly Press, Washington, D.C.

Braak CJF ter \& Šmilauer P (1998) CANOCO reference manual and user's guide to Canoco for Windows: software for canonical community ordination (Version 4). Center for Biometry Wageningen and Microcomputer Power, Ithaca, NY.

Cook ER \& Holmes RL (1996) Guide for computer program ARSTAN: The international tree ring data bank program library version 2.0 user's manual (ed. by HD Grissino-Mayer, RL Holmes \& HC Fritts) Laboratory of Tree-Ring Research, University of Arizona, Tucson, AZ, USA, pp. 75-87.

Dunwiddie PW (1979) Dendrochronological studies of indigenous New Zealand trees. New Zealand Journal of Botany 17: 251-266.

Farjon A (2001) World checklist and bibliography of conifers. 2nd ed. Kew Royal Botanic Gardens.

Farjon A \& Page CN (1999) Conifers. Status survey and conservation action plan. IUCN/SSC Conifer Specialist Group, IUCN, Gland, Switzerland and Cambridge, UK.

February EC \& Stock WD (1998) An assessment of the dendrochronological potential of two Podocarpus species. The Holocene 8: 747-750.

Gerding V, Geldres E \& Moya JA (2006) Diagnóstico del desarrollo de Pinus massoniana y Pinus brutia establecidos en el arboreto de la Universidad Austral de Chile, Valdivia. Bosque 27: 57-63.

González-Reyes A \& Muñoz AA (2013) Cambios en la precipitación de la ciudad de Valdivia (Chile) durante los últimos 150 años. Bosque 34: 200213.

Graham EA, Mulkey SS, Kitajima K, Phillips NG \& Wright SJ (2003) Cloud cover limits net $\mathrm{CO}_{2}$ uptake and growth of a rainforest tree during tropical rainy seasons. Proceedings of the National Academy of Sciences USA 100: 572-576.

Grissino-Mayer HD (2001) Evaluating crossdating accuracy: a manual and tutorial for the computer program COFECHA. Tree-Ring Research 57: 205-221.

Guay R, Gagnon R \& Morin H (1992) A new automatic and interactive tree-ring measurement system based on a line scan camera. The Forestry Chronicle 68: 138-141.

Hechenleitner P, Gardner MF, Thomas PI, Echeverría C, Escobar B, Brownless P \& Martínez C (2005) Plantas Amenazadas del Centro-Sur de Chile. 
Distribución, Conservación y Propagación. 1st ed. Universidad Austral de Chile y Real Jardín Botánico de Edimburgo.

Kelch DG (1997) The phylogeny of the Podocarpaceae based on morphological evidence. Systematic Botany 22: 113-131.

Krepkowski J, Bräuning A \& Gebrekirstos A (2012) Growth dynamics and potential for cross-dating and multi-century climate reconstruction of Podocarpus falcatus in Ethiopia. Dendrochronologia 30: 257-265.

Krepkowski J, Braüning A, Gebrekirstos A \& Strobl S (2011) Cambial growth dynamics and climatic control of different tree life forms in tropical mountain forest in Ethiopia. Trees 25: 59-70.

Lamprecht AM (1984) Dendroklimatologische Untersuchungen in Südamerika. Swiss Federal Institute of Forestry Research Report 263, Birmensdorf, Switzerland.

Legendre P \& Legendre L (1998) Numerical ecology, 2nd English edn. Developments in Environmental Modelling, number 20. Elsevier, Amsterdam.

Le Quesne C, Stahle D, Cleaveland M, Therrell M, Aravena JC \& Barichivich J (2006) Ancient Austrocedrus tree-ring chronologies used to reconstruct Central Chile precipitation variability from A.D. 1200 to 2000. Journal of Climate 19: 5731-5744.

Mäkinen H, Nöjd P, Kahle HP, Neumann U, Tveite B, Mielikäinen K, Röhle H \& Spiecker H (2002) Radial growth variation of Norway spruce (Picea abies (L.) Karst.) across latitudinal and altitudinal gradients in central and northern Europe. Forest Ecology and Management 171: 233-249.

McDougall KL, Brookhouse MT \& Broome LS (2012) Dendroclimatological investigation of mainland Australia's only alpine conifer, Podocarpus lawrencei Hook. Dendrochronologia 30: 1-9.

Min Q \& Wang S (2008) Clouds modulate terrestrial carbon uptake in a midlatitude hardwood forest. Geophysical Research Letters 35: L02406. doi:10.1029/2007GL032398.

Muñoz AA, Barichivich J, Christie DA, Dorigo W, Sauchyn D, González-Reyes A, Villalba R, Lara A, Riquelme N \& González ME (2014) Patterns and drivers of Araucaria araucana forest growth along a biophysical gradient in the northern $\mathrm{Pa}$ tagonian Andes: linking tree-rings with satellite observations of soil moisture. Austral Ecology 39: 158-169.
Norton DA \& Ogden J (1990) Problems with the use of tree rings in the study of forest population dynamics: Methods of dendrochronology - applications in the environmental sciences (ed. by ER Cook \& LA Kairiukstis) Kluwer Academic Publishers, Dordrecht, pp. 284-288.

Norton DA, Palmer JG \& Ogden J (1987) Dendroecological studies in New Zealand 1. An evaluation of tree age estimates based on increment cores. New Zealand Journal of Botany 25: 373-383.

Ögren E (1997) Relationship between temperature, respiratory loss of sugar and premature dehardening in dormant Scots pine seedlings. Tree Physiology 17: 47-51.

Peterson DW \& Peterson DL (2001) Mountain hemlock growth responds to climatic variability at annual and decadal time scales. Ecology 82: 33303345.

Rathgeber CBK, Rossi S \& Bontemps JD (2011) Cambial activity related to tree size in a mature silver-fir plantation. Annals of Botany 108: 429-438.

Rodríguez R, Matthei O \& Quezada M (1983) Flora arbórea de Chile. Editorial de la Universidad de Concepción, Universidad de Concepción, Chile.

Rozas V, García-González I, Pérez-de-Lis G \& Arévalo JR (2013) Local and large-scale climatic factors controlling tree-ring growth of Pinus canariensis on an oceanic island. Climate Research 56: 197-207.

Rozas V, Zas R \& García-González I (2011) Contrasting effects of water availability on Pinus pinaster radial growth near the transition between the Atlantic and Mediterranean biogeographical regions in NW Spain. European Journal of Forest Research 130: 959-970.

Speer JH (2010) Fundamentals of Tree Ring Research. University of Arizona Press, Tucson, AZ, USA.

Sweda T \& Inoue J (1987) Dendrochronologies of San Rafael and Soler areas, Patagonia. Bulletin of Glacier Research 4: 125-132.

Thomsen G (2001) Response to winter precipitation in ring-width chronologies of Pinus sylvestris L. from the northwestern Siberian plain, Russia. Tree-Ring Research 57: 15-29.

Wells JA (1972) Ecology of Podocarpus hallii in Central Otago, New Zealand. New Zealand Journal of Botany 10: 399-426. 